\title{
Clinicopathological and prognostic significance of microRNA-107 and its relationship to DICER1 mRNA expression in gastric cancer
}

\author{
TAISUKE INOUE, HISAE IINUMA, ETSUSHI OGAWA, TSUYOSHI INABA and RYOJI FUKUSHIMA \\ Department of Surgery, Teikyo University School of Medicine, Tokyo 173-0003, Japan
}

Received September 5, 2011; Accepted November 4, 2011

DOI: $10.3892 /$ or.2012.1709

\begin{abstract}
RNAs (miRNAs) are small non-coding RNAs that regulate target gene expression. It is known that miRNA-107 (miR-107) promotes cancer invasion and metastasis. However, the relationship between clinicopathological factors and the prognostic significance of miR-107 for gastric cancer patients remains elusive. In this study, we evaluated the prognostic value of miR-107 using tissue samples from gastric cancer patients. Furthermore, the relationship between miR-107 and the mRNA levels of its target gene DICER1 was examined. The expression levels of miR-107 and DICER1 mRNA in tumor tissues and adjacent normal tissues of 161 gastric cancer patients were examined (TNM stage I, 29 patients; stage II, 31 patients; stage III, 51 patients and stage IV, 50 patients). miR-107 levels were measured by TaqMan microRNA assays, and DICER1 mRNA levels were measured by the TaqMan real-time RT-PCR method. In the analysis by real-time PCR-based miRNA arrays using pooled RNA samples from five gastric cancer patients, expression of miR-107, miR-21, miR-196a, miR-26b, miR-9, miR-142-3p, miR-30b, miR-150, miR-191 and miR-17 was found to be upregulation. The mean expression level of miR-107 was significantly higher in the tumor tissues compared to that of normal tissues. In the comparison of clinicopathological factors, $\mathrm{miR}-107$ expression showed significant association with depth of tumor invasion, lymph node metastasis and stage. In Kaplan-Meier survival curve analysis, overall survival rates (OS) and disease-free survival rates (DFS) of patients with high miR-107 expression were significantly worse than those of patients with low miR-107 expression. In the Cox multivariate analysis, it was shown that miR-107 expression in gastric cancer tissues was an independent prognostic factor for OS and DFS. Significant
\end{abstract}

Correspondence to: Dr Hisae Iinuma, Department of Surgery, Teikyo University School of Medicine, 2-11-1 Kaga, Itabashi-ku, Tokyo 173-0003, Japan

E-mail: iinuma@med.teikyo-u.ac.jp

Abbreviations: RT-PCR, reverse transcription-polymerase chain reaction; miRNA, microRNA

Key words: gastric cancer, microRNA-107, DICER1, recurrence, prognosis inverse correlations were demonstrated between miR-107 and DICER1 mRNA. Our results indicate that miR-107 may be useful as an effective biomarker for prediction of a poor prognosis in gastric cancer patients.

\section{Introduction}

Gastric cancer is one of the most common cancers in Japan and other East Asian countries (1). Despite significant investment and advances in the management of gastric cancer, the survival rates for patients with advanced stages of the disease have changed little over the past 10 years (2). As such, a biomarker for selection of high-risk patients with poor prognosis is highly desirable.

microRNAs (miRNAs) are small 21-25 nucleotides of RNA that participate in the regulation of cell differentiation, cell cycle progression, apoptosis and tumorigenesis (3-8). The study of microRNA has been extended to many types of cancer. miRNAs target protein-coding mRNAs at the post-transcriptional level by direct cleavage of the mRNA or by inhibition of protein synthesis $(9,10)$. Recent evidence indicates that various miRNAs can function as oncogenes or tumor-suppressor genes and play a central role in carcinogenesis (5). Accumulating evidence shows that miR-107 is one of the oncogenic RNAs, and overexpression of these RNAs has been reported in several types of human malignant solid tumors, including gastric, esophageal, pancreatic and colorectal cancer (10-16). Moreover, miR-107 may contribute to the regulation of the cell cycle in non-small cell lung cancer cell lines (17). It was reported that miR-107 can mediate p53 regulation of hypoxic signaling and tumor angiogenesis (18). Additionally, miRNAs may be useful tools for characterizing specific cancers and for determining patient prognosis and response to therapy (3-8). In gastric cancer, it has been shown that overexpression of miR-107 is associated with metastasis (13). However, the association between the miR-107 expression, clinicopathological characteristics and the prognostic value of miR-107 in gastric cancer has not yet been reported.

miRNAs exert their biological effects by targeting specific mRNAs. DICER1 is known as one of the target genes of miR-107 (13). Dicer is the enzyme responsible for the cleavage of miRNA precursors. Growing evidence suggests that DICER1 expression levels are associated with worse clinical outcomes in various cancer types (19-22). However, there are few studies concerning the correlation between DICER1 
mRNA and miR-107 in clinical samples of gastric cancer patients.

In the present study, we investigated miR-107 expression in tumor tissues from 161 gastric cancer patients to determine its clinicopathological and prognostic significance. We also examined the association between the mRNA expression of miR-107 and DICER1, which is one of the target genes of miR-107.

\section{Materials and methods}

Patients and tissue samples. In this study, 161 gastric cancer patients were enrolled between 2000 and 2005 at Teikyo University Hospital. The stages of the gastric cancer patients were evaluated by TNM staging (stage I, 29 patients; stage II, 31 patients; stage III, 51 patients and stage IV, 50 patients). The median follow-up period was 40 months (range, 6-72 months). Primary tumor tissues and matched normal tissues adjacent to the tumor tissues (normal tissues) of gastric cancer patients were collected. All samples were derived from patients who had not received chemotherapy prior to surgery. Immediately following surgical resection, tissues were frozen in liquid nitrogen until use. The study protocol conformed to the guidelines of the ethics committee. It was approved by the Review Board of Teikyo University, and written informed consent was obtained from all patients.

Real-time PCR-based miRNA array. miRNA expression profiling was performed using cancer microRNA qPCR array with the QuantiMir system (System Biosciences, Mountain View, CA, USA). This system is a real-time PCR-based array containing a panel of 95 cancer-related mature miRNA assays and the U6 transcript as a normalization signal. In brief, total RNA containing small RNA extracted from tissue samples was first polyadenylated by poly(A)polymerase and then reverse transcribed to cDNA using a mixture of oligo-dT adaptor. The cDNA then served as the template for SYBR real-time PCR using Power SYBR Master Mix (Applied Biosystems, Inc., Foster City, CA, USA), using miRNA-specific primers provided by the manufacturer. SYBR-PCR was performed using a LightCycler 480 Real-Time PCR system (Roche Applied Science, Indianapolis, IN, USA). $\Delta \Delta \mathrm{CT}$ was calculated by subtracting the $\mathrm{CT}$ values of $\mathrm{U} 6$ from the $\mathrm{CT}$ values of the gene of interest. $\Delta \Delta \mathrm{CT}$ was then calculated by subtracting $\Delta \mathrm{CT}$ of the control from $\Delta \mathrm{CT}$ of the sample. The fold change of the gene was calculated by the equation: $2^{-\Delta \Delta \mathrm{CT}}$.

TaqMan microRNA assay. Total RNAs, including the miRNAs, were extracted from 161 primary tissues and matched normal tissues of gastric cancer patients using the miRNeasy Mini Kit (Qiagen Inc., Valencia, CA, USA). The miR-107 and RNU6Bspecific cDNA were synthesized using gene-specific primer sets according to the TaqMan microRNA assay protocol (Applied Biosystems). RNU6B was used as an internal control. In brief, reverse transcriptase reactions contained $10 \mathrm{ng}$ of total RNAs, $50 \mathrm{nmol} / \mathrm{stem}$-loop RT primer, 1X RT buffer, $0.25 \mathrm{mmol} / 1$ each of deoxynucleotide triphosphate (dNTP), $3.33 \mathrm{U} / \mu 1$ MultiScribe reverse transcriptase, and $0.2 \mathrm{U} / \mu 1$ RNase inhibitor. The 7.5- $\mu 1$ reaction samples were incubated in GeneAmp PCR System 9700 (Applied Biosystems) for
Table I. Ten most highly upregulated miRNAs in the gastric cancer samples as determined by real-time PCR-based miRNA profiling array.

\begin{tabular}{llc}
\hline microRNA & mirBase no. & Fold-change \\
\hline miR-107 & MIMAT0000104 & 4.13 \\
miR-21 & MIMAT0000076 & 4.11 \\
miR-196a & MIMAT0000226 & 4.06 \\
miR-26b & MIMAT0000083 & 3.74 \\
miR-9 & MIMAT0000441 & 3.35 \\
miR-142-3p & MIMAT0000434 & 3.21 \\
miR-30b & MIMAT0000420 & 3.19 \\
miR-150 & MIMAT0000451 & 2.76 \\
miR-191 & MIMAT0000440 & 2.53 \\
miR-17 & MIMAT0000070 & 2.13 \\
\hline
\end{tabular}

$\mathrm{n}=5$.

$30 \mathrm{~min}$ at $16^{\circ} \mathrm{C}, 30 \mathrm{~min}$ at $42^{\circ} \mathrm{C}, 5 \mathrm{~min}$ at $85^{\circ} \mathrm{C}$, and then folded at $4^{\circ} \mathrm{C}$. Quantitative real-time PCR was performed using ABI StepOne (Applied Biosystems). The $10 \mu \mathrm{l}$ PCR samples included $0.67 \mu \mathrm{l}$ of RT products, $1 \mathrm{X}$ TaqMan Universal PCR Master Mix, and $1 \mu \mathrm{l}$ of primers, and the probe mix was incubated in 48 -well optical plates. The PCR conditions were $95^{\circ} \mathrm{C}$ for $10 \mathrm{~min}$, followed by 40 cycles of $95^{\circ} \mathrm{C}$ for $15 \mathrm{sec}$ and $60^{\circ} \mathrm{C}$ for $6 \mathrm{sec}$. All the experiments were undertaken in triplicate. Relative quantification of miRNA expression was calculated using the $2^{-\Delta \Delta \mathrm{CT}}$ method, where $\Delta \Delta \mathrm{CT}=\Delta \mathrm{CT}\left(\mathrm{CT}_{\mathrm{miR} 107}{ }^{-}\right.$ $\left.\mathrm{CT}_{\mathrm{RNU6B}}\right)_{\text {tumor tissues }}-\Delta \mathrm{CT}\left(\mathrm{CT}_{\text {miR107 }}-\mathrm{CT}_{\mathrm{RNU6B}}\right)_{\text {normal tissues }}$.

Quantitative real-time $R T$-PCR for DICER1 $m R N A$. Total RNAs were extracted using the miRNeasy Mini Kit and complementary DNA (cDNA) synthesis was performed using random hexamer primers and SuperScript II reverse transcriptase according to the manufacturer's protocol (Invitrogen Corp., Carlsbad, CA, USA). Quantitative real-time PCR amplification (qRT-PCR) of DICER1 and GAPDH mRNA (internal control) were measured using a LightCycler 480 Real-Time PCR system. The amplifications of DICER1 and GAPDH mRNA were performed using the TaqMan primer and probe set (Applied Biosystems). The PCR conditions for DICER1 mRNA were $95^{\circ} \mathrm{C}$ for $10 \mathrm{~min}$, followed by 35 cycles at $95^{\circ} \mathrm{C}$ for $10 \mathrm{sec}, 65^{\circ} \mathrm{C}$ for $10 \mathrm{sec}$, and $72^{\circ} \mathrm{C}$ for $10 \mathrm{sec}$. The PCR products were then subjected to a temperature gradient from 68 to $95^{\circ} \mathrm{C}$ at $0.1 / \mathrm{sec}$, with continuous fluorescence monitoring to produce melting curves of the products. All the experiments were performed in triplicate. The expression levels of DICER1 mRNA were normalized to GAPDH mRNA expression.

Statistical analysis. The relationships between miR-107 expression and clinicopathological factors were analyzed using the Student's t-test, the $\chi^{2}$ test and ANOVA. Overall survival (OS) and disease-free survival (DFS) curves were analyzed using the Kaplan-Meier method, and the differences were examined using log-rank tests. Cox proportional-hazards regression analysis was applied in order to estimate univariate 


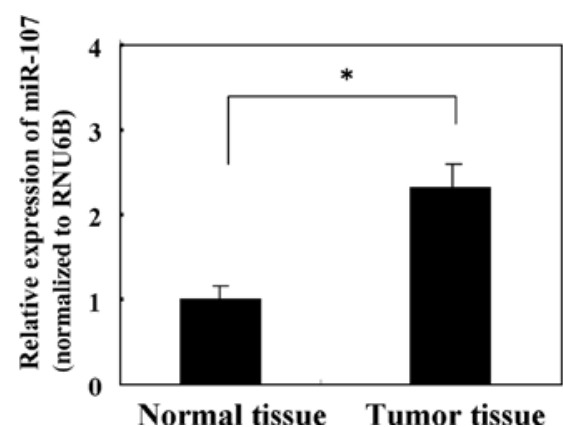

Figure 1. Comparison of miR-107 expression between gastric cancer and normal tissues. Relative miR-107 levels were determined in 161 gastric cancer patients and expressed as fold change after normalization to RNU6B. Data are expressed as the mean \pm standard error (SE). Expression of miR-107 in tumor tissues was significantly higher than that in normal tissues. " $\mathrm{p}<0.001$.

and multivariate hazard ratios for OS and DFS. All p-values are two-sided, and $\mathrm{p}<0.05$ was considered to denote statistical significance. Statistical analyses were carried out using JMP 9.0 software (SAS Institute Inc., Cary NC, USA).

\section{Results}

Selection of microRNAs for gastric cancer. First, we examined the profiling of miRNA expression in gastric cancer tissues using the real-time PCR-based miRNA arrays containing a panel of 95 cancer-related mature miRNAs. In this assay, we used pooled RNA samples of primary gastric cancer tissues and normal tissues from five patients. Normal tissues that were adjacent to tumor tissues were collected from the same patients. Table I shows the ten miRNAs which were highly upregulated in this assay. miR-107, miR-21, miR-196a, miR-26b, miR-9, miR-142-3p, miR-30b, miR-150, miR-191 and miR-17 were included in this list. Our results showed that the highest upregulation for miR107 as compared with the other miRNAs. On the basis of these profiling results and other information from published studies, we selected miR-107 as the marker for gastric cancer and used it for subsequent study.

Expression of miR-107 in tumor and normal tissues. Fig. 1 shows a comparison of miR-107 expression levels in the gastric cancer and normal tissues. The mean $( \pm \mathrm{SE})$ expression level of miR-107 was significantly higher in the tumor tissues $(2.32 \pm 0.29)$ than that in the normal tissues $(1.14 \pm 0.17)$ $(\mathrm{p}<0.001)$.

Relationship between clinicopathological factors and miR-107 expression in the tumor tissues. This study examined a total of 161 gastric cancer patients ( 97 men and 64 women) with a mean age of 67 years (range, 35-87). To evaluate the correlation between the miR-107 expression levels and the clinicopathological characteristics, patients were divided into two groups (high and low). The cut-off levels for miR-107 were set at 2.74 , which is the mean level of relative quantity $\left(2^{-\Delta \Delta \mathrm{CT}}\right)$ according to a previously published study (23). As shown in Table II, a statistically significant association was observed between miR-107 expression and depth of tumor invasion, lymph node metastasis and TNM stage.

Correlation between miR-107 levels and OS and DFS. KaplanMeier OS and DFS curves of the gastric cancer patients according to the status of miR-107 levels were examined (Fig. 2). For OS analysis, all 161 patients were included, and 111 patients who underwent curative surgery were included for DFS analysis. The OS of patients in the high miR-107 group showed significantly worse survival rates than those who were in the low miR-107 group ( $\mathrm{p}=0.002$ ) (Fig. 2A). DFS analysis revealed that the patients in the high miR-107 group had significantly worse survival rates than those who were in the low miR-107 group ( $\mathrm{p}=0.017$ ) (Fig. 2B). These results suggest that high expression of miR-107 is associated with poor prognosis in gastric cancer patients.

Univariate and multivariate Cox analysis of prognostic factors in $O S$ and DFS. The results of univariate and multivariate Cox proportional hazard regression analysis for OS and DFS are shown in Tables III and IV. Multivariate analysis was performed for factors that showed significance in univariate analysis. In the univariate analysis, miR-107, tumor size, depth of invasion, lymph node metastasis, lymphatic invasion, venous invasion and stage showed significance for OS (Table III). In the multivariate analysis, miR-107, venous invasion and stage showed significance for OS. In the univariate analysis for DFS, miR-107, lymph node metastasis, venous invasion and stage
A OS

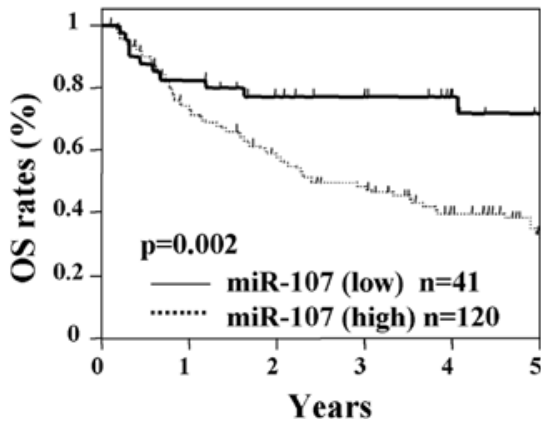

B

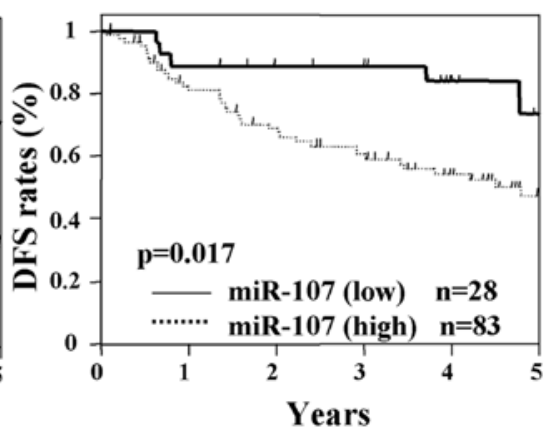

Figure 2. Kaplan-Meier survival curves of OS and DFS based on miR-107 expression. The gastric cancer patients were divided into two groups: a low miR-107 group and a high-miR107 group. The OS (A) and DFS (B) of patients in the high miR-107 group showed significantly worse survival rates than those in the low miR-107 group. 
Table II. Relationship between clinicopathological features and miR-107 expression in gastric cancer tissues.

\begin{tabular}{|c|c|c|c|c|}
\hline \multirow[b]{2}{*}{ Features } & \multirow[b]{2}{*}{$\begin{array}{c}\text { Patients } \\
\mathrm{n}(\%)\end{array}$} & \multicolumn{2}{|c|}{ miR-107 expression } & \multirow[b]{2}{*}{$\mathrm{p}$-value } \\
\hline & & $\begin{array}{l}\text { High } \\
\mathrm{n}(\%)\end{array}$ & $\begin{array}{l}\text { Low } \\
\mathrm{n}(\%)\end{array}$ & \\
\hline Total no. & 161 & 120 & 41 & \\
\hline \multicolumn{5}{|l|}{ Tumor size (cm) } \\
\hline$<5$ & $40(24.84)$ & $27(16.77)$ & 13 (8.07) & 0.247 \\
\hline$\geq 5$ & $121(75.16)$ & $93(57.76)$ & $28(17.39)$ & \\
\hline \multicolumn{5}{|l|}{ Histological type } \\
\hline Well-differentiated & $19(11.80)$ & $13(8.07)$ & $6 \quad(3.73)$ & 0.523 \\
\hline Poorly differentiated & $142(88.20)$ & $107(66.46)$ & $35(21.74)$ & \\
\hline \multicolumn{5}{|l|}{ Depth of invasion } \\
\hline pT1 & $11 \quad(6.83)$ & $5 \quad(3.11)$ & $6 \quad(3.73)$ & $0.033^{\mathrm{a}}$ \\
\hline$>\mathrm{pT} 2$ & $150(93.17)$ & $115(71.43)$ & 35 (21.74) & \\
\hline \multicolumn{5}{|l|}{ Lymphatic invasion } \\
\hline Absent & $38(23.60)$ & $25(15.53)$ & 13 (8.07) & 0.166 \\
\hline Present & $123(76.40)$ & $95(59.01)$ & $28(17.39)$ & \\
\hline \multicolumn{5}{|l|}{ Venous invasion } \\
\hline Absent & 37 (22.98) & $23(14.29)$ & 14 (8.70) & 0.059 \\
\hline Present & $124(77.02)$ & $97(60.25)$ & 27 (16.77) & \\
\hline \multicolumn{5}{|l|}{ Lymph node metastasis } \\
\hline Absent & $29(18.01)$ & 16 (9.94) & $13(8.07)$ & $0.012^{\mathrm{a}}$ \\
\hline Present & $132(81.99)$ & $104(64.60)$ & $28(17.39)$ & \\
\hline \multicolumn{5}{|l|}{ Liver metastasis } \\
\hline Absent & $150(93.17)$ & $114(70.81)$ & $36(22.36)$ & 0.136 \\
\hline Present & $11 \quad(6.83)$ & $6 \quad(3.73)$ & $5 \quad(3.11)$ & \\
\hline \multicolumn{5}{|c|}{ Peritoneum dissemination } \\
\hline Absent & $146(90.68)$ & $109(67.70)$ & $37(22.98)$ & 0.911 \\
\hline Present & $15(9.32)$ & $11(6.83)$ & $4 \quad(2.48)$ & \\
\hline \multicolumn{5}{|l|}{ Stage } \\
\hline I & $29(18.01)$ & $15 \quad(9.32)$ & 14 (8.70) & $0.010^{\mathrm{a}}$ \\
\hline II & $31(19.25)$ & $24(14.91)$ & $7 \quad(4.35)$ & \\
\hline III & $51(31.68)$ & $44(27.33)$ & $7 \quad(4.35)$ & \\
\hline IV & $50(31.06)$ & 37 (22.98) & $13(8.70)$ & \\
\hline
\end{tabular}

${ }^{\mathrm{a}} \mathrm{p}<0.05$.

showed significance (Table IV). In the multivariate analysis, miR-107 and stage showed significance for DFS. These results suggest that miR-107 has independent prognostic value for both OS and DFS.

Correlations of miR-107 levels and target genes. The correlation between miR-107 and DICER1 mRNA level was examined. As shown in Fig. 3, a significant inverse correlation was shown between miR-107 and DICER1 mRNA $(\gamma=-0.522$, $\mathrm{p}<0.001)$. These results suggest that the expression of DICER1 mRNA may be negatively regulated by miR-107.

\section{Discussion}

In this study, we demonstrated that the expression of miR-107 in gastric cancer tissue has a significant prognostic value for OS and DFS. Furthermore, miR-107 expression in gastric cancer tissues showed a significant negative association with DICER1 mRNA levels.

A number of studies have shown that miRNAs serve functionally as oncogenes or tumor-suppressor genes and regulate multiple cellular processes relevant to tumorigenesis and cancer progression (24). In this study, we focused on the 
Table III. Univariate and multivariate analysis of prognostic factors in for overall survival.

\begin{tabular}{|c|c|c|c|c|c|c|}
\hline \multirow[b]{2}{*}{ Variables } & \multicolumn{3}{|c|}{ Univariate analysis } & \multicolumn{3}{|c|}{ Multivariate analysis } \\
\hline & $\begin{array}{l}\text { Regression } \\
\text { coefficient }\end{array}$ & $\begin{array}{l}\text { Hazard ratio } \\
(95 \% \mathrm{CI})\end{array}$ & P-value & $\begin{array}{l}\text { Regression } \\
\text { coefficient }\end{array}$ & $\begin{array}{l}\text { Hazard ratio } \\
(95 \% \mathrm{CI})\end{array}$ & P-value \\
\hline Tumor size & 0.849 & $2.338(1.335-4.436)$ & $0.002^{\mathrm{a}}$ & 0.407 & $1.502(0.829-2.938)$ & 0.187 \\
\hline Depth of invasion & 1.559 & $4.756(1.495-28.945)$ & $0.005^{\mathrm{a}}$ & -0.116 & $0.891(0.212-6.055)$ & 0.888 \\
\hline Lymph node metastasis & 1.492 & $4.448(1.991-12.671)$ & $<0.001^{\mathrm{a}}$ & -0.078 & $0.925(0.285-3.259)$ & 0.898 \\
\hline Lymphatic invasion & 0.771 & $2.162(1.232-4.109)$ & $0.006^{\mathrm{a}}$ & 0.158 & $1.171(0.647-2.286)$ & 0.617 \\
\hline Venous invasion & 1.374 & $3.952(2.022-8.915)$ & $<0.001^{\mathrm{a}}$ & 0.786 & $2.194(1.058-5.220)$ & $0.034^{\mathrm{a}}$ \\
\hline Histological type & 0.189 & $1.208(0.619-2.723)$ & 0.604 & & $(-)$ & \\
\hline Stage & 1.916 & $6.795(3.728-13.648)$ & $<0.001^{\mathrm{a}}$ & 1.578 & $4.845(2.266-11.865)$ & $<0.001^{\mathrm{a}}$ \\
\hline miR-107 & -1.023 & $0.360(0.174-0.665)$ & $0.001^{\mathrm{a}}$ & -0.793 & $0.452(0.217-0.845)$ & $0.011^{\mathrm{a}}$ \\
\hline
\end{tabular}

${ }^{\mathrm{a}} \mathrm{p}<0.05$.

Table IV. Univariate and multivariate analysis of prognostic factors for disease-free survival

\begin{tabular}{|c|c|c|c|c|c|c|}
\hline \multirow[b]{2}{*}{ Variables } & \multicolumn{3}{|c|}{ Univariate analysis } & \multicolumn{3}{|c|}{ Multivariate analysis } \\
\hline & $\begin{array}{c}\text { Regression } \\
\text { coefficient }\end{array}$ & $\begin{array}{l}\text { Hazard ratio } \\
(95 \% \mathrm{CI})\end{array}$ & P-value & $\begin{array}{c}\text { Regression } \\
\text { coefficient }\end{array}$ & $\begin{array}{l}\text { Hazard ratio } \\
(95 \% \mathrm{CI})\end{array}$ & P-value \\
\hline Tumor size & 0.679 & $1.971(0.984-4.383)$ & 0.056 & & $(-)$ & \\
\hline Depth of invasion & 0.989 & $2.688(0.824-16.525)$ & 0.112 & & $(-)$ & \\
\hline Lymph node metastasis & 1.010 & $2.745(1.183-7.982)$ & $0.017^{\mathrm{a}}$ & -0.362 & $0.696(0.129-3.771)$ & 0.659 \\
\hline Lymphatic invasion & 0.143 & $1.154(0.612-2.299)$ & 0.665 & & $(-)$ & \\
\hline Venous invasion & 1.010 & $2.746(1.293-6.759)$ & $0.007^{\mathrm{a}}$ & 0.390 & $1.477(0.591-4.487)$ & 0.424 \\
\hline Histological type & 0.413 & $1.511(0.607-5.045)$ & 0.407 & & $(-)$ & \\
\hline Stage & 1.589 & $4.900(2.527-10.242)$ & $<0.001^{\mathrm{a}}$ & 1.582 & $4.863(1.648-20.817)$ & $0.003^{\mathrm{a}}$ \\
\hline miR-107 & -1.081 & $0.339(0.117-0.788)$ & $0.010^{\mathrm{a}}$ & -1.974 & $0.139(0.008-0.670)$ & $0.009^{\mathrm{a}}$ \\
\hline
\end{tabular}

${ }^{\mathrm{a}} \mathrm{p}<0.05$.

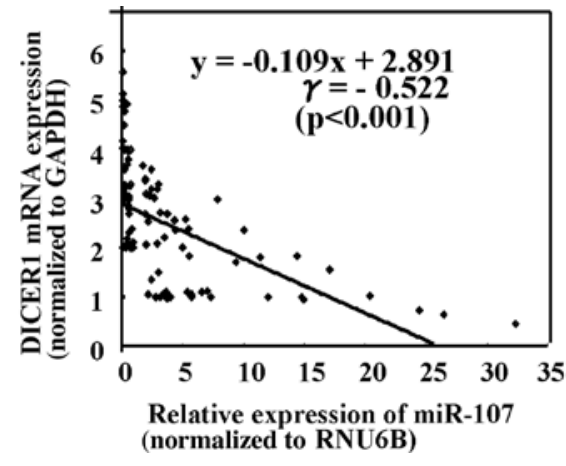

Figure 3. Correlation between miR-107 and DICER1 mRNA expression. The correlation between miR-107 and DICER1 mRNA levels was examined. A significant inverse correlation was demonstrated between miR-107 and DICER1 mRNA levels.

characteristics of miR-107 in gastric cancer tissues based on the results of miRNA profiling by real-time PCR array.
Many studies have demonstrated overexpression of miR-107 in gastric, esophageal, colon, hepatocellular and pancreatic cancers, suggesting that this miRNA has some positive role in the carcinogenesis of these cancers (10-16). It has been reported that miR-107 is an oncogenic miRNA that regulates tumor invasion and metastasis in gastric cancer (13). Our results also showed that the miR-107 expression level in gastric cancer tissues was significantly higher in tumor tissues than in normal tissues. However, little is known about the association between clinicopathological factors and miR-107 in this type of cancer. We first demonstrated that miR-107 expression is significantly associated with depth of tumor invasion, lymph node metastasis and stage.

The potential value of miRNAs as prognostic biomarkers are of interest. Yet, there has been only one study that has attempted to identify the prognostic value of miR-107 for gastric cancer patients. Using a small number of gastric cancer patients (50 cases), Li et al analyzed the Kaplan-Meier analysis results and showed that lower miR-107 expression was associated with poorer survival (13). However, they did not investigate the Cox 
multivariate analysis of miR-107. In contrast, in our present study of 161 gastric cancer patients, we analyzed not only the Kaplan-Meier survival curve but also applied Cox multivariate analysis to clarify the prognostic value of miR-107. Notably, we found that higher expression levels of miR-107 in gastric cancer tissues significantly correlated with poorer OS and DFS. Furthermore, in Cox multivariate analysis, miR-107 expression in gastric cancer tissues showed a significant association with OS and DFS. Although, our results are different from those of Li et al, our results support the hypothesis that miR-107 promotes gastric cancer metastasis by downregulation of DICER1 (13). However, an explanation for the discrepancy in the survival results between ours and other studies must await further research. To the best of our knowledge, our study is the first to show the independent prognostic value of miR-107 in gastric cancer patients.

miRNAs exert their biological effects by targeting proteincoding-specific mRNAs in two different ways: one by direct cleavage of the target mRNAs and the other by inhibition of protein synthesis (8). Recently, Li et al demonstrated that miR-107 regulates tumor invasion and metastasis by targeting DICER1 in gastric cancer (13). Dicer is the enzyme responsible for the cleavage of miRNA precursors and it is necessary for the production of mature miRNAs (25). DICER1 is capable of splicing the hairpin-like structure RNA and double-strand RNA into mature 21-nt miRNA or siRNA. Although research on the association of DICER 1 with disease is limited, DICER1 appears to play an important role in the development of cancer (18-21). A different transcription initiation site and splicing of the DICER1 gene which may result in poor protein translation and stability of mRNA and subsequent lower expression of DICER1 in cancer cells was suggested (26). Furthermore, DICER1 expression was found to be decreased during the progression of gastric cancer (27). However, little is known concerning the relationship between miR-107 and DICER1 mRNA expression in clinical samples of gastric cancer patients. In the present study, we examined the relationship between miR-107 and DICER1 mRNA levels, and demonstrated a significant inverse correlation.

In conclusion, our data indicate that overexpression of miR-107 in gastric cancer tissues has prognostic value and that these molecules may have useful therapeutic applications in the future.

\section{Acknowledgements}

We thank J. Tamura for her excellent technical assistance, and all members of the gastrointestinal group for sampling and clinical suggestions. This study was supported by a Grantin-Aid for Scientific Research (C) (21591734).

\section{References}

1. Uemura N, Okamoto S, Yamamoto S, et al: Helicobacter pylori infection and the development of gastric cancer. N Engl J Med 345: 784-789, 2001.
2. Crew KD and Neugut AI: Epidemiology of gastric cancer. World J Gastroenterol 12: 354-362, 2006.

3. Medina PP and Slack FJ: microRNA and cacer: an overview. Cell Cycle 7: 2485-2492, 2008.

4. Paranjape T, Slack FJ and Weidhaas JB: MicroRNAs: tools for cancer diagnostics. Gut 58: 1546-1554, 2009.

5. Esquela-Kerscher A and Slack FJ: Oncomirs - microRNAs with a role in cancer. Nat Rev Cancer 6: 259-269, 2006.

6. Chen CZ, Li L, Lodish HF and Bartel DP: MicroRNAs modulate hematopoietic lineage differentiation. Science 303: 83-86, 2004.

7. Croce $\mathrm{CM}$ and Calin GA: miRNAs cancer and stem cell division. Cell 122: 6-7, 2005.

8. Mattick JS and Makunin IV: Non-coding RNA. Hum Mol Genet 15: R17-R29, 2006.

9. Bartel DP: MicroRNAs: genomics, biogenesis, mechanism, and function. Cell 116: 281-297, 2004.

10. Volinia S, Calin GA, Liu CG, et al: A microRNA expression signature of human solid tumors defines cancer gene targets. Proc Natl Acad Sci USA 103: 2257-2261, 2006.

11. Huang XH, Wang Q, Chen JS, et al: Bead-based microarray analysis of microRNA expression in hepatocellular carcinoma: miR-338 is downregulated. Hepathol Res 39: 786-794, 2009.

12. Guo Y, Chen A, Zhang L, et al: Distinctive microRNA profiles relating to patient survival in esophageal squamous cell carcinoma. Cancer Res 68: 26-33, 2008.

13. Li X, Zhang Y, Shi Y, et al: MicroRNA-107, an oncogene microRNA that regulates tumor invasion and metastasis by targeting DICER1 in gastric cancer. J Cell Mol Med 15: 1887-1895, 2011.

14. Li X, Zhang Y, Ding J, et al: Survival prediction of gastric cancer by a seven-microRNA signature. Gut 59: 579-585, 2010.

15. Lu J, Getz G, Miska EA, et al: MicroRNA expression profiles classify human cancers. Nature 435: 834-838, 2005.

16. Lee KH, Lotterman C, Karikari C, et al: Epigenetic silencing of microRNA-107 regulates cyclin-dependent kinase 6 expression in pancreatic cancer. Pancreatology 9: 293-301, 2009.

17. Takahashi Y, Forrest ARR, Maeno E, et al: MiR-107 and mir-185 can induce cell cycle arrest in human non-small cell lung cancer cell lines. PLoS One 4: 1-9, 2009.

18. Yamakuchi M, Lotterman CD, Bao C, et al: p53-induced microRNA-107 inhibits HIF-1 and tumor angiogenesis. Proc Natl Acad Sci USA 107: 6334-6339, 2010.

19. Karube Y, Tanaka H, Osada H, et al: Reduced expression of Dicer is associated with poor prognosis in lung cancer patients. Cancer Sci 96: 111-115, 2005.

20. Merritt WM, Lin YG, Han LY, et al: Dicer, Drosha, and outcomes in patients with ovarian cancer. N Engl J Med 359: 2641-2650, 2008.

21. Chiosea S, Jelezcova E, Chandran U, et al: Up-regulation of dicer, a component of the microRNA machinery, in prostate adenocarcinoma. Am J Pathol 169: 1812-1820, 2006.

22. Chiosea S, Jelezcova E, Chandran U, et al: Overexpression of Dicer in precursor lesions of lung adenocarcinoma. Cancer Res 67: 2345-2350, 2007.

23. Shibuya H, Iinuma H, Shimada R, et al: Clinicopathological and prognostic value of microRNA-21 and microRNA-155 in colorectal cancer. Oncology 79: 313-320, 2010.

24. Hwang HW and Mendell JT: MicroRNAs in cell proliferation, cell death, and tumorigenesis. Br J Cancer 94: 776-780, 2006.

25. Kumar MS, Pester RE, Chen CY, et al: Dicer1 functions as a haploinsufficient tumor suppressor. Genes Dev 23: 2700-2704, 2009.

26. Zighelboim I, Reinhart AJ, Gao F, et al: DICER1 expression and outcome in endometrioid endometrial adenocarcinoma. Cancer 117: 1446-1453, 2011.

27. Zheng ZH, Sun XJ, Fu WN, et al: Decreased expression of DICER1 in gastric cancer. Chin Med J 120: 2099-2104, 2007. 